Erratum

\title{
Erratum to "Hydroxychloroquine Effects on TLR Signalling: Underexposed but Unneglectable in COVID-19"
}

\author{
Aliede E. in 't Veld ${ }^{1},{ }^{1,2}$ Manon A. A. Jansen, ${ }^{1}$ Luuk C. A. Ciere ${ }^{(D)}{ }^{1}$ \\ and Matthijs Moerland ${ }^{1,2}$ \\ ${ }^{1}$ Centre of Human Drug Research, Leiden, Netherlands \\ ${ }^{2}$ Leiden University Medical Center, Leiden, Netherlands \\ Correspondence should be addressed to Matthijs Moerland; mmoerland@chdr.nl
}

Received 23 April 2021; Accepted 23 April 2021; Published 17 May 2021

Copyright (c) 2021 Aliede E. in 't Veld et al. This is an open access article distributed under the Creative Commons Attribution License, which permits unrestricted use, distribution, and reproduction in any medium, provided the original work is properly cited.

In the article titled "Hydroxychloroquine Effects on TLR Signalling: Underexposed but Unneglectable in COVID-19" [1], the incorrect file for Figure 2 was used during the production process and the figure should be corrected as follows: 


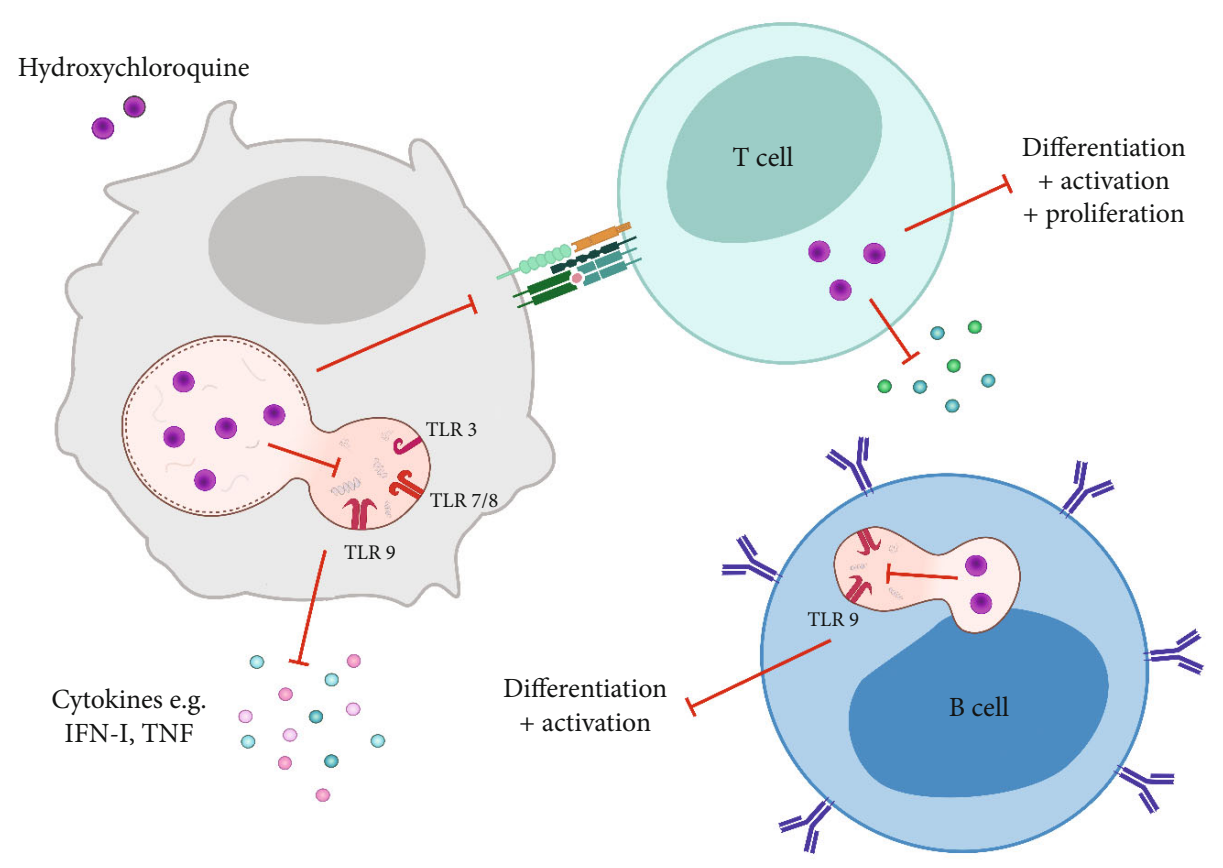

Figure 2

\section{References}

[1] A. E. in 't Veld, M. A. A. Jansen, L. C. A. Ciere, and M. Moerland, "Hydroxychloroquine Effects on TLR Signalling: Underexposed but Unneglectable in COVID-19," Journal of Immunology Research, vol. 2021, Article ID 6659410, 7 pages, 2021. 